\title{
Prediction of Polyethylene Wear Rates from Gait Biomechanics and Implant Positioning in Total Hip Replacement
}

\author{
Marzieh M. Ardestani PhD, Pedro P. Amenábar Edwards MD, Markus A. Wimmer PhD
}

Received: 26 September 2016/ Accepted: 17 February 2017/Published online: 2 March 2017

(C) The Association of Bone and Joint Surgeons \& 2017

\begin{abstract}
Background Patient-specific gait and surgical variables are known to play an important role in wear of total hip replacements (THR). However a rigorous model, capable of predicting wear rate based on a comprehensive set of subject-specific gait and component-positioning variables, has to our knowledge, not been reported.

Questions/purpose (1) Are there any differences between patients with high, moderate, and low wear rate in terms of gait and/or positioning variables? (2) Can we design a model to predict the wear rate based on gait and positioning
\end{abstract}

Each author certifies that he or she, or a member of his or her immediate family, has no funding or commercial associations (eg, consultancies, stock ownership, equity interest, patent/licensing arrangements, etc) that might pose a conflict of interest in connection with the submitted article.

All ICMJE Conflict of Interest Forms for authors and Clinical Orthopaedics and Related Research ${ }^{\mathbb{R}}$ editors and board members are on file with the publication and can be viewed on request.

Clinical Orthopaedics and Related Research ${ }^{\circledR}$ neither advocates nor endorses the use of any treatment, drug, or device. Readers are encouraged to always seek additional information, including FDAapproval status, of any drug or device prior to clinical use.

Each author certifies that his or her institution approved or waived approval for the human protocol for this investigation and that all investigations were conducted in conformity with ethical principles of research.

This work was performed at the Department of Orthopedic Surgery, Rush University Medical Center, Chicago, IL, USA.

M. M. Ardestani, M. A. Wimmer ( $\square)$

Department of Orthopedics, Human Motion Analysis and

Tribology, Rush University Medical Center, 1611 W. Harrison

St, Suite 204, Chicago, IL 60612, USA

e-mail: markus_a_wimmer@rush.edu

P. P. Amenábar Edwards

Departamento de Traumatología y Ortopedia, Pontificia

Universidad Católica de Chile, Santiago, Chile variables? (3) Which group of wear factors (gait or positioning) contributes more to the wear rate?

Patients and Methods Data on patients undergoing primary unilateral THR who performed a postoperative gait test were screened for inclusion. We included patients with a 28-mm metal head and a hip cup made of noncrosslinked polyethylene (GUR 415 and 1050) from a single manufacturer (Zimmer, Inc). To calculate wear rates from radiographs, inclusion called for patients with a series of standing radiographs taken more than 1 year after surgery. Further, exclusion criteria were established to obtain reasonably reliable and homogeneous wear readings. Seventythree (83\% of included) patients met all criteria, and the final dataset consisted of 43 males and 30 females, $69 \pm 10$ years old, with a BMI of $27.3 \pm 4.7 \mathrm{~kg} / \mathrm{m}^{2}$. Wear rates of these patients were determined based on the relative displacement of the femoral head with regard to the cup using a validated computer-assisted X-ray wear-analysis suite. Three groups with low $(<0.1 \mathrm{~mm} /$ year $)$, moderate $(0.1$ to $0.2 \mathrm{~mm} /$ year), and high (>0.2 mm/year) wear were established. Wear prediction followed a two-step process: (1) linear discriminant analysis to estimate the level of wear (low, moderate, or high), and (2) multiple linear and nonlinear regression modeling to predict the exact wear rate from gait and implant-positioning variables for each level of wear.

Results There were no group differences for positioning and gait suggesting that wear differences are caused by a combination of wear factors rather than single variables. The linear discriminant analysis model correctly predicted the level of wear in $80 \%$ of patients with low wear, $87 \%$ of subjects with moderate wear, and $73 \%$ of subjects with high wear based on a combination of gait and positioning variables. For every wear level, multiple linear and nonlinear regression showed strong associations between gait 
biomechanics, implant positioning, and wear rate, with the nonlinear model having a higher prediction accuracy. Flexion-extension ROM and hip moments in the sagittal and transverse planes explained $42 \%$ to $60 \%$ of wear rate while positioning factors, (such as cup medialization and cup inclination angle) explained only $10 \%$ to $33 \%$.

Conclusion Patient-specific wear rates are associated with patients' gait patterns. Gait pattern has a greater influence on wear than component positioning for traditional metal-on-polyethylene bearings.

Clinical Relevance The consideration of individual gait bears potential to further reduce implant wear in THR. In the future, a predictive wear model may identify individual, modifiable wear factors for modern materials.

\section{Introduction}

In many patients, a total hip replacement (THR) does not last for a lifetime and revision surgery is becoming more common [29]. For traditional THR that used noncrosslinked polyethylene liners, loosening and/or osteolysis account for nearly $30 \%$ of all performed revisions [9]. With the introduction of crosslinked polyethylene, the wear rate has been greatly reduced even in the young active population [22]; however, at this time it is unclear if the loosening or lysis problem has been solved or just has been delayed to the second or third decade of the lifetime of the prosthesis. Therefore, it makes sense to further investigate the factors governing wear in the hopes of keeping them under control.

Many factors contribute to polyethylene wear, including implant design variables (geometric features and material properties) $[1,2,23,28,31,36]$, surgical variables (implantation method and component positioning) [15, 16], and patient factors [10, 14, 39]. Regarding patient factors, gait and motion patterns have been shown to affect the hip contact force, one of the variables that influences polyethylene wear $[20,21]$. Two studies showed that the inclusion of patientspecific factors in hip-wear simulation yielded to clinically relevant wear results $[27,30]$. However, it is not possible to comprehensively account for large interpatient variability in gait and implant positioning in simulators owing to machine time and costs. Therefore, computational models such as finite element analyses have been used to model the influence of gait cycle [32], implant orientation [18, 19, 44], and joint loading parameters [17, 34]. Despite these previous efforts, a predictive wear model, based on a comprehensive set of patient-specific gait and component-positioning variables, is not available. Further, from a technical viewpoint, most predictive models rely on multiple linear regression modeling which does not fully accommodate the existing nonlinearities of the complex interactions between wear factors and wear rate.

Using repository data of patients who had THR, we therefore asked the following questions: (1) Are there any differences between patients who had THR with high, moderate, and low wear rate in terms of gait and/or positioning variables? (2) Using statistical models, such as regression models, can we predict the wear rate based on gait and positioning variables? (3) Which group of wear factors (gait or positioning) contributes more to the wear rate?

\section{Patients and Methods}

\section{Patients}

All patients who had THR who had performed a gait test and were listed in the institutional review board-approved data repository at the Motion Analysis Lab at Rush University Medical Center were reviewed. All patients provided written consent for inclusion. Patients with unilateral hip arthroplasty and with one or more gait trials 10 months or more after surgery (to ascertain recovery from surgery) and a minimum of 3 years of clinical followup (that needed to be available and documented in the orthopaedic tissue, implant, and information repository) qualified for inclusion. Two senior surgeons (JOG and AGR) performed the majority of the procedures $(>90 \%)$ and used a posterior and an anterolateral approach, respectively. To control for the most important design and material variables for THR wear between head and cup, inclusion was further restricted to patients with a $28-\mathrm{mm}$ cobalt-chromium metal ball and a liner made of noncrosslinked polyethylene (GUR 415 and 1050) that was housed in a fiber mesh titanium cup (Zimmer, Inc, Warsaw, IN, USA). While all cups were cementless and shared a similar design philosophy, various cemented and cementless stems were used (Table 1). Finally, to calculate a meaningful wear rate (defined as head penetration into the polyethylene liner with time), inclusion called for patients with at least two AP view standing radiographs, taken at least 1 year apart with the first radiograph taken after the bedding-in phase 1 year or more after surgery. This led to the immediate inclusion of 88 patients from the repository.

Exclusion criteria were established to obtain reasonably reliable and homogeneous wear readings: (1) patients with a negative wear rate (implying material gain or growth which is physically impossible), (2) patients with wear readings for which the interobserver correlation coefficient (ICC) was less than 0.90, and (3) patients with extreme outliers of wear (ie, more than three times the interquartile range from the rest of the wear readings) as identified from 


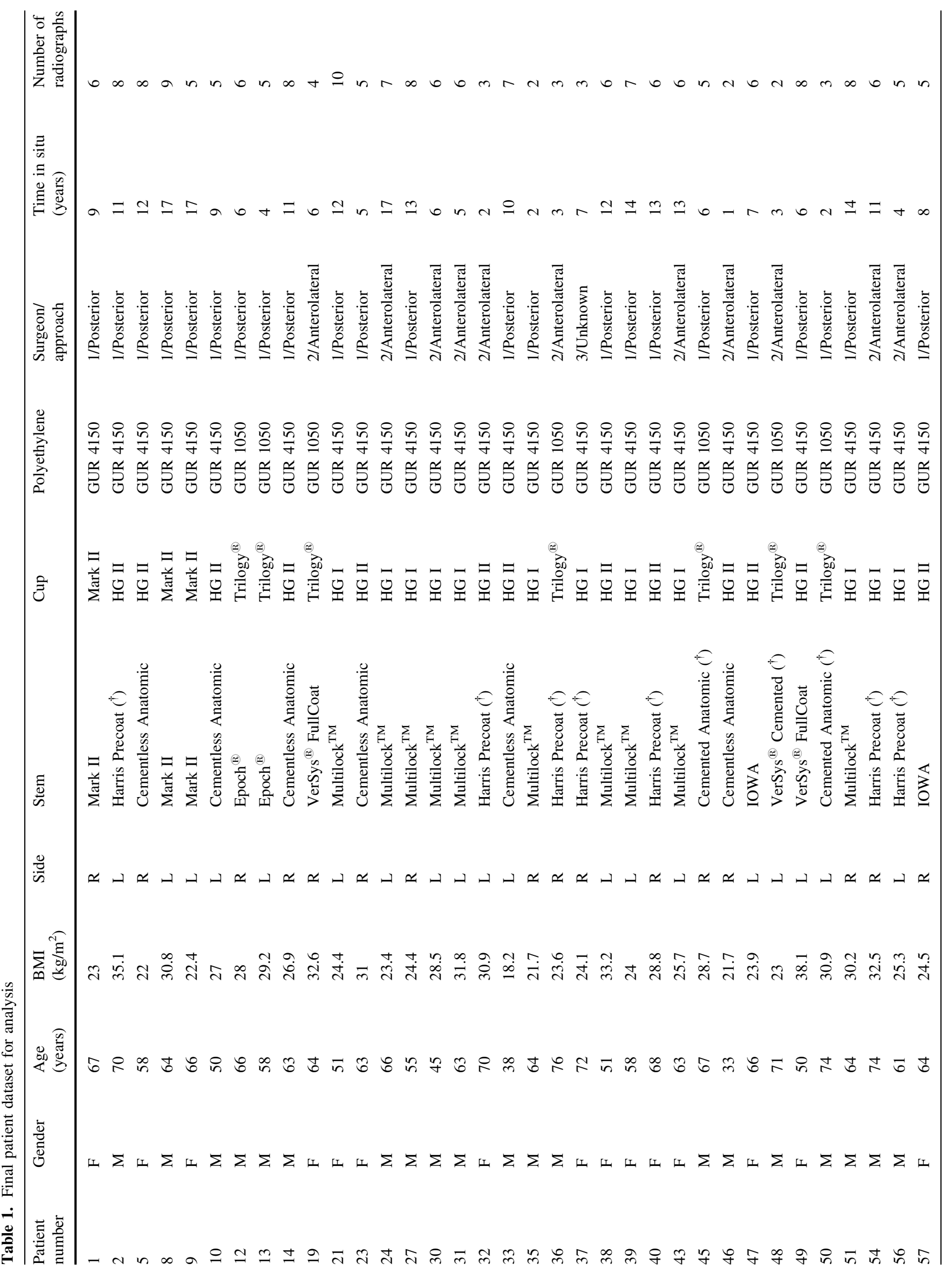




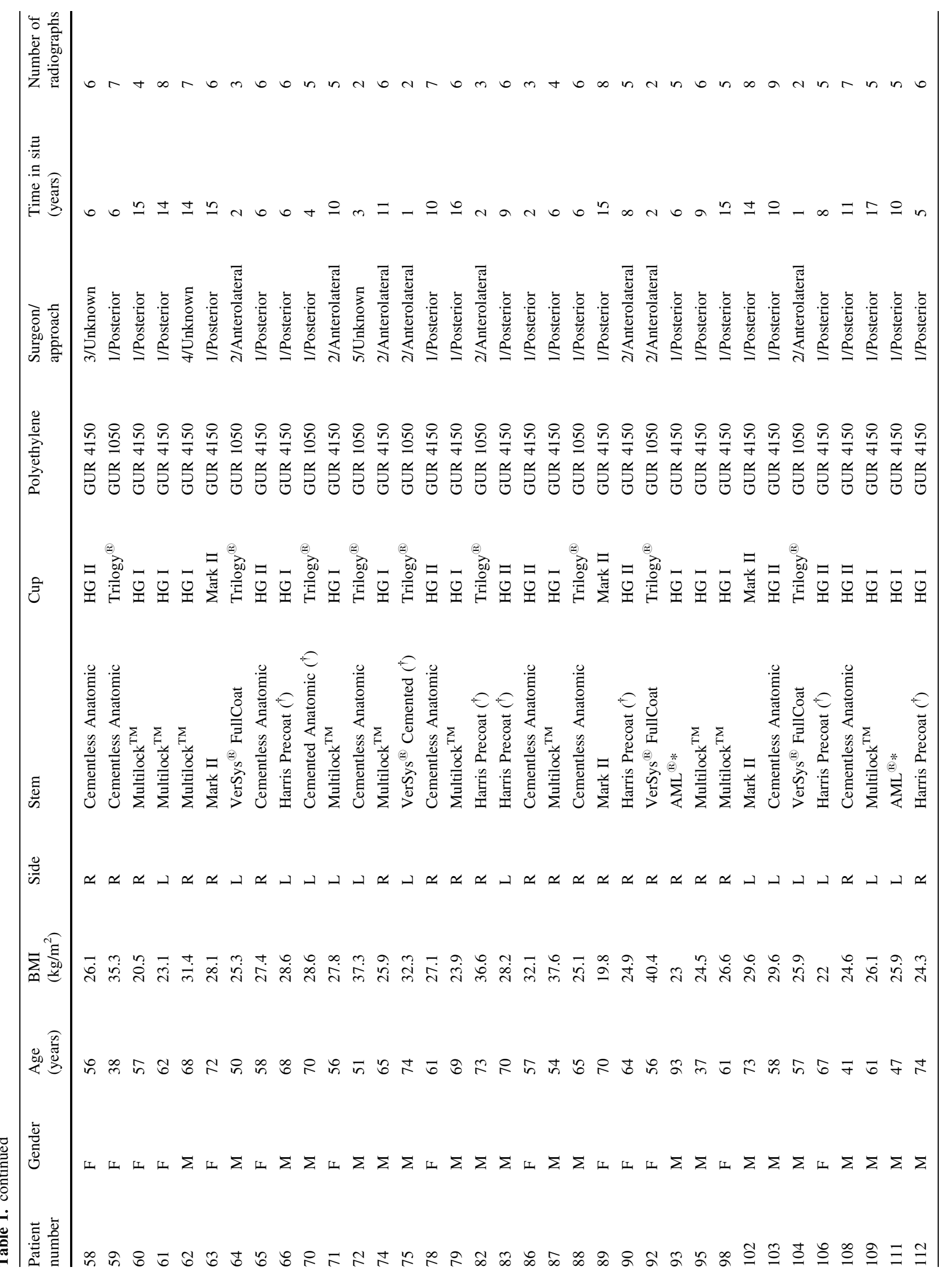




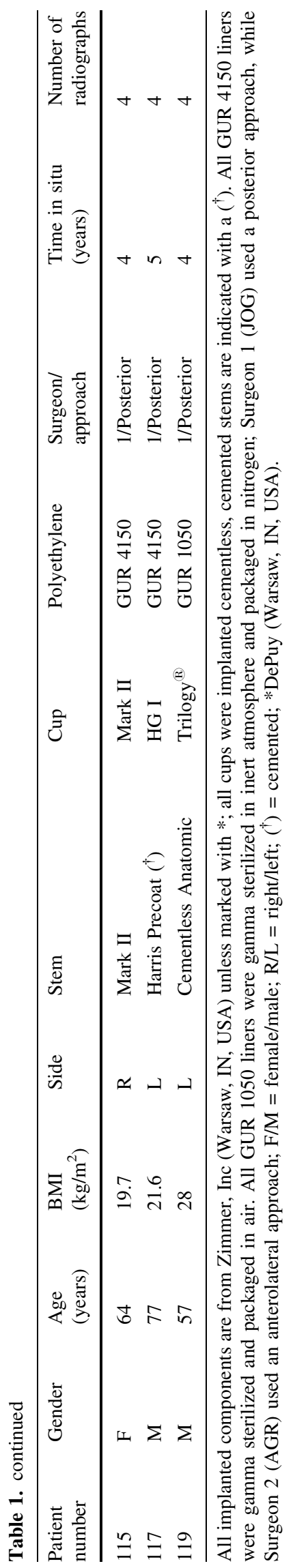

box plots (SPSS Version 15.0; SPSS Inc, Chicago, IL, USA). These criteria led to the exclusion of 15 patients: four patients were excluded owing to negative wear readings, nine were excluded owing to low ICC wear readings (0.2-0.77), and two were excluded owing to wear readings classified as outliers (68 and $97 \mathrm{~mm} /$ year). This left 73 patients (83\% of the included) for analysis: 43 males and 30 females, $69 \pm 10$ years old, and BMI of $27.3 \pm 4.7 \mathrm{~kg} /$ $\mathrm{m}^{2}$. These patients had their implants 10 to 123 months (average, $37 \pm 31$ months) in situ and had two to 10 radiographs acquired every 9 to 20 months during followups (Table 1).

\section{Gait Analysis}

Gait data had been collected from 1990 through 2004 using a four-camera motion-capture system with passive markers (120 frames per second) (Qualisys, Gothenburg, Sweden) and a multicomponent force plate (Bertec Corporation, Colombus, OH, USA) for measurement of ground reaction forces. A total of six retroreflective markers were placed on the lateral aspect of the iliac crest, superior aspect of the greater trochanter, mid-point of the lateral joint line of the knee, lateral malleolus, head of the fifth metatarsal, and the lateral aspect of the calcaneus. Patients were required to be pain free at the date of the gait test. During gait analysis patients walked at three self-selected speeds of "normal", "slow", and "fast" with multiple trials collected at each speed. The trial with median speed was chosen as the most representative from the patients' self-selected "normal speed" trials.

To calculate external forces and moments, the lower extremities were modeled as a collection of three rigid links (thigh, shank, and foot). This link model assumed that no axial rotation occurred about the long axes of the segments. The hip center was assumed to be at a point $2.5 \mathrm{~cm}$ below the mid-point of a line that runs from the anterior superior iliac crest to the pubic tubercle [3]. The inertial properties for each segment were lumped at its mass center and were used in the calculations for the external moments. Inverse dynamics was used to calculate the external moments in all three dimensions about the hip centers [3]. The external moments included the moment about the joint center created by the ground reaction force and inertial forces of the body segments. The external moments were transformed into a local coordinate system aligned with the femur. A total of seven gait variables (Table 2) were extracted for each patient that were considered for further analysis: hip range of motion (HROM), maximum hip flexion moment (HMXFLEX), maximum hip extension moment (HMXEXT), maximum hip adduction moment (HMYADD), maximum hip abduction moment (HMYABD), maximum hip internal rotation moment (HMZINT), and maximum hip external rotation moment (HMZEXT). 
Table 2. Summary of wear factor abbreviations and descriptions

\begin{tabular}{ll}
\hline $\begin{array}{l}\text { Wear factor and } \\
\text { abbreviation }\end{array}$ & Description \\
\hline Gait variable & \\
HROM & Sagittal hip range of motion \\
HMXFLEX & Maximum hip flexion moment \\
HMXEXT & Maximum hip extension moment \\
HMYADD & Maximum hip adduction moment \\
HMZINT & Maximum hip internal rotation \\
& moment \\
HMZEXT & Maximum hip external rotation \\
Component positioning & moment \\
C-INCL & Cup inclination \\
C-ANTE & Cup anteversion \\
C-MED & Cup medialization \\
V-SET & Vertical offset \\
H-SET & Horizontal offset \\
ABD-L & Abductor lever arm \\
\hline
\end{tabular}

\section{Wear Analysis}

A computer-assisted technique (Hip Analysis Suite; UChicagoTech, Chicago, IL, USA) was used to determine the relative, linear displacement ("penetration") of the metal ball into the polyethylene liner from digital radiographs. The measured penetration correlates with material removal (wear) from the polyethylene liner, as previously described and validated by Martell and Berdia [33] and Berzins et al. [11]. Standard AP radiographs with the patient in a standing position were obtained from the repository for all included patients. The radiographic films were converted to digital format using a flatbed scanner (Vision Ten Inc, Carlstadt, NJ, USA). Typically, during the first year after surgery, embedding of the articulating components takes place. Therefore, it is likely that the actual wear rate is masked. For this reason, only radiographs after the first year of surgery were chosen. Moreover, because wear rates, determined from shorter implant duration times, may tend to be higher, the association between wear rate and the length of followup (time in situ) was investigated using a linear regression model. Ideally, several (minimum two) radiographs were available to determine the wear rate using a linear regression model. Two observers (PPAE and DB) independently measured the wear rate using the Hip Analysis Suite. Only subjects with ICCs of the wear readings greater than 0.90 were included in the study. There were nine patients for whom the ICC was less than 0.9 (range, 0.50-0.75). These patients were excluded from the study.

\section{Component Positioning}

Vertical joint-center position was measured as the superoinferior distance between the center of the head and the interteardrop line of the pelvis while the horizontal position was measured as the mediolateral distance between the center of the head and the teardrop. A line connecting the most-lateral aspect of the greater trochanter and Charnley's origin of the abductors (defined at a location $2.5 \mathrm{~cm}$ medial and $2.5 \mathrm{~cm}$ superior to the inferior portion of the anterior superior iliac spine) was drawn to represent the line of action of the abductor muscles [12]. A line perpendicular to this line was drawn through the center of the femoral heads to represent the abductor lever arm (ABD-L) (Fig. 1A). The contralateral hip center was identified computationally using the Hip Analysis Suite by a three-point click on the native femoral head.

The horizontal offset (H-SET) was defined as the mediolateral distance between the center of the head and the anatomic axis of the femur [25] (Fig. 1A). Vertical offset (V-SET) was identified by drawing a line through the center of the head and perpendicularly on the femoral implant axis. The offset is the perpendicular distance between the center of the head and the implant axis (Fig. 1B). Cup medialization (C-MED) was measured as the distance between the medial wall of the acetabulum and the center of the cup (Fig. 1A). The cup anteversion (CANTE) was estimated as the angle formed by the long axis of the cup component and the line connecting the top point of the ellipse and the endpoint of the long axis (Fig. 1C). Cup inclination (C-INCL) was defined as the angle between the longitudinal axis of the patient and the radiographic projection of the acetabular axis, that is, perpendicular to the major axis of the cup projection [42] (Fig. 1D). All measurements were expressed in degrees and millimeters after correction for magnification.

\section{Wear Predictive Model}

Before proposing the wear predictive model, and to avoid inclusion of redundant variables, potential collinearity among gait variables and among positioning variables was investigated using the variance inflation factor (VIF) as the investigative tool. Each of the seven gait variables (or six positioning variables) was considered as the output of a linear regression model and all other remaining gait variables (or remaining positioning variables) served as predictors. Only gait variables (or positioning variables) for which all other gait (or positioning) variables yielded a VIF less than 2.5 were considered independent and entered in the wear predictive model. 
Fig. 1A-D Component positioning factors consisted of the (A) abductor lever arm (1), horizontal offset (2), and cup medialization (3), (B) vertical offset (4), (C) cup anteversion (5), and (D) cup inclination (6)
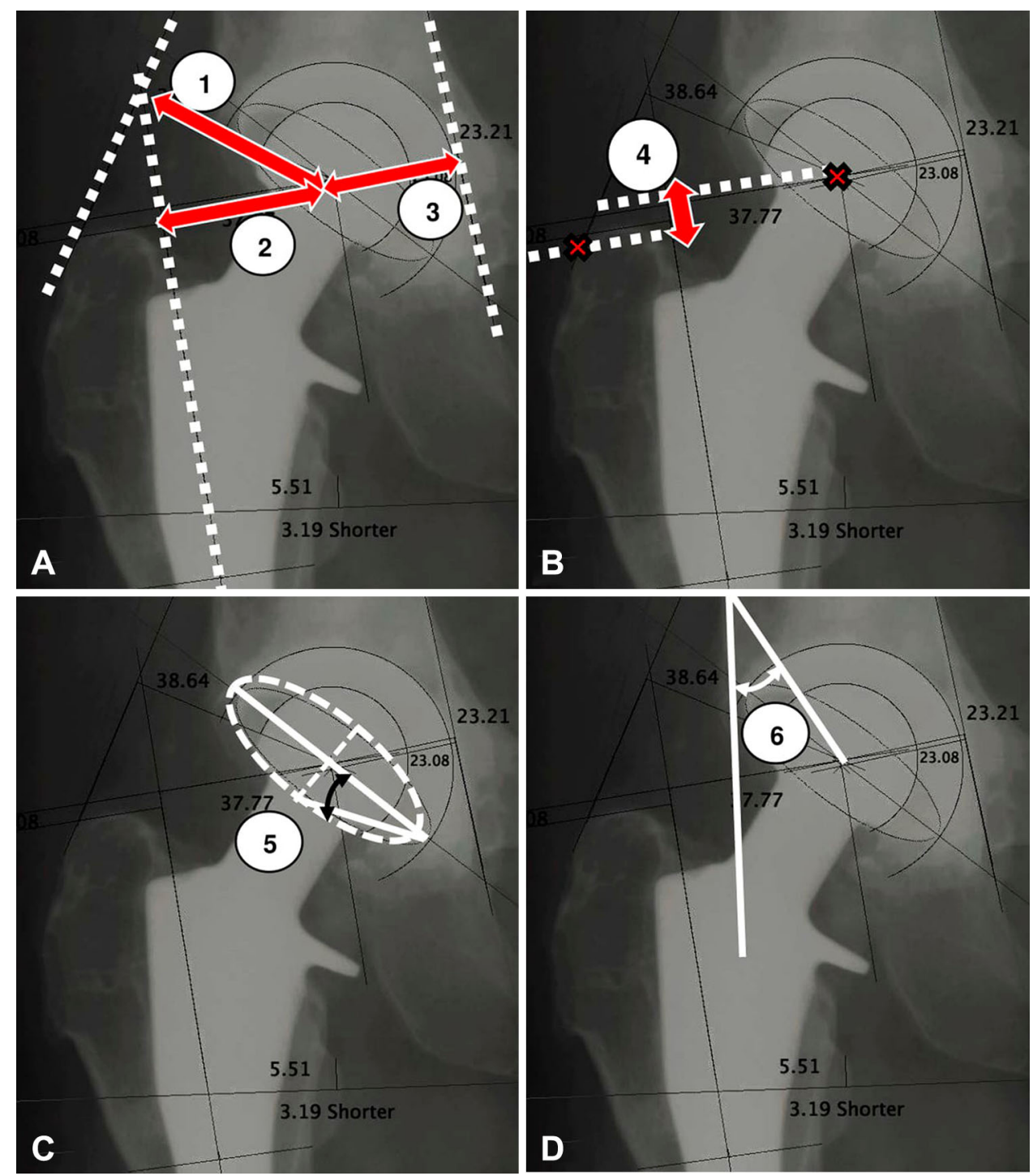

The proposed predictive model consisted of two parts: (1) predicting the level of wear rate (high, moderate, or low) using a linear classifier (ie, linear discriminant analysis (LDA) [35]) and (2) predicting the amount of wear rate using a multiple linear regression (MLR) and/or nonlinear regression in form of an artificial neural network (ANN) model. The level of wear rate was considered "low" when the linear wear rate was less than $0.1 \mathrm{~mm}$ per year; "moderate" when the linear wear rate was more than 0.1 mm per year and less than $0.2 \mathrm{~mm}$ per year; and "high" when the linear rate was greater than $0.2 \mathrm{~mm}$ per year. This classification criterion was obtained from a study in which noncrosslinked UHMWPE wear less than $0.1 \mathrm{~mm}$ per year was considered "low" and a wear rate greater than $0.2 \mathrm{~mm}$ per year was associated with osteolysis and subsequent component loosening [41]. Using these criteria, our 73 patients with THRs were divided in three groups: 25 patients with low-wear rate (wear rate, $0.06 \pm 0.02 \mathrm{~mm} /$ year; age, $63.7 \pm 7.8$ years; BMI, $\left.27.3 \pm 4.3 \mathrm{~kg} / \mathrm{m}^{2}\right), 29$ patients with moderate-wear rate (wear rate, $0.15 \pm 0.03 \mathrm{~mm} /$ year; age, $60.4 \pm$
10.7 years; BMI, $26.5 \pm 4.7 \mathrm{~kg} / \mathrm{m}^{2}$ ); and 19 patients with highwear rate (wear rate, $0.27 \pm 0.04 \mathrm{~mm} /$ year; age, $58.3 \pm 9.8$ years; BMI, $28.6 \pm 5.1 \mathrm{~kg} / \mathrm{m}^{2}$ ) (Table 3).

The LDA model consisted of three classification rules; one rule per wear group (low, moderate, and high wear). Each rule was a linear combination of the wear factors and calculated a membership score for each patient. Patients then were assigned to the wear group whose classification rule led to the highest membership score. To establish this classifier, patients were randomly divided into two subsets: $80 \%$ of the patients were used to establish the classification rules and the remaining $20 \%$ of patients were used to test whether the classifier could correctly classify new patients (test dataset). The classification accuracy of the LDA model was defined as the number of correctly classified patients divided by the number of total test patients. To achieve a 95\% CI about the classification accuracy, the training and testing procedures were iterated until all 
Table 3. Demographic description of three classes (mean \pm SD)

\begin{tabular}{lllllll}
\hline Group & Number of patients & Age (years) & Height $(\mathrm{m})$ & BMI $\left(\mathrm{kg} / \mathrm{m}^{2}\right)$ & Speed $(\mathrm{m} /$ second) & Linear wear rate $(\mathrm{mm} / \mathrm{year})$ \\
\hline Low wear & 25 & $63.7 \pm 7.8$ & $1.7 \pm 0.07$ & $27.3 \pm 4.3$ & $1.1 \pm 0.1$ & $0.06 \pm 0.02$ \\
Moderate wear & 29 & $60.4 \pm 10.7$ & $1.7 \pm 0.08$ & $26.5 \pm 4.7$ & $1.1 \pm 0.1$ & $0.1 \pm 0.03$ \\
High wear & 19 & $58.3 \pm 9.8$ & $1.7 \pm 0.08$ & $28.6 \pm 5.1$ & $1.1 \pm 0.2$ & $0.3 \pm 0.04$ \\
\hline
\end{tabular}

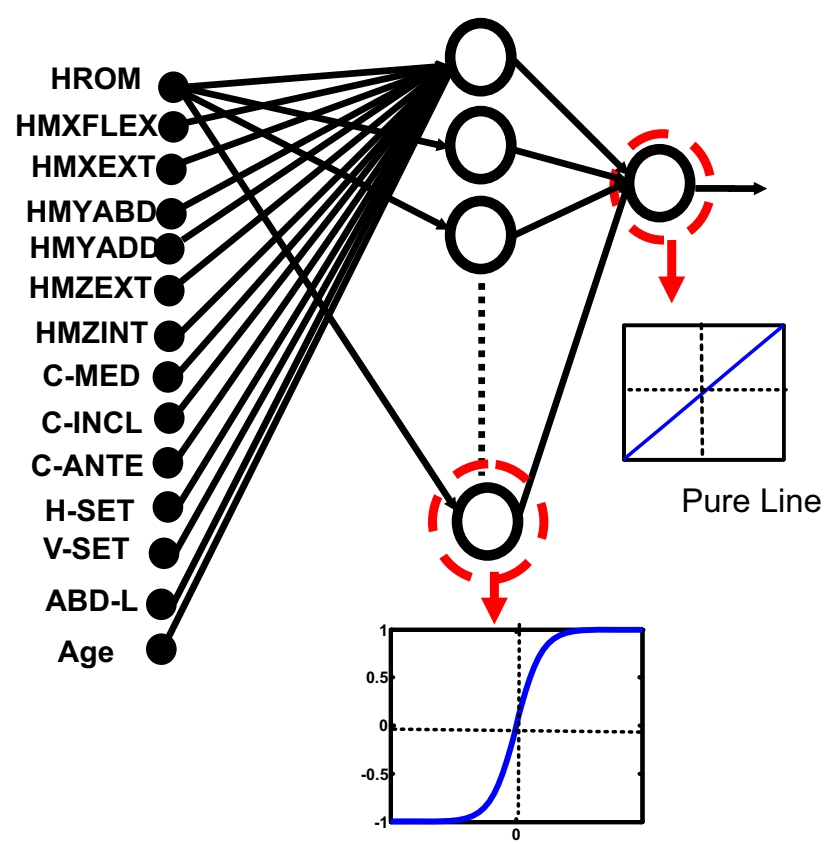

Hyperbolic Tangent Sigmoid

Fig. 2 The proposed three-layer artificial neural network had 14 input nodes including hip range of motion (HROM), hip flexion moment (HMXFLEX), hip extension moment (HMXEXT), hip abduction moment (HMYABD), hip adduction moment (HMYADD), hip hip external rotation (HMZEXT), internal rotation (HMZINT), cup medialization (C-MED), cup inclination (C-INCL), cup anteversion (C-ANTE), horizontal offset (H-SET), vertical offset (V-SET), abductor lever arm (ABD-L), and subject age (Age).

participants were used as test data. The classification accuracy then was averaged over all the iterations.

Once classified, the wear rate of each patient was predicted using MLR and ANN models. Considering that the level of patient activity plays a central role in wear of the polyethylene liner, and age has been shown to be a surrogate of patient activity [37], age was included as a factor, together with gait and positioning variables. For the MLR, the relationship between wear factors (that is, age, seven gait variables, and six positioning variables) and wear rate was modeled by fitting a linear equation to the observations of each wear group:

$$
\text { Wear rate }=\alpha_{1} \times \mathrm{x}_{1}+\alpha_{2} \times \mathrm{x}_{2}+\alpha_{3} \times \mathrm{x}_{3}+\cdots+\alpha_{14}
$$$$
\times \mathrm{x}_{14}+\beta
$$

Where $x_{1}$ to $x_{14}$ represent the wear factors (age, gait, and component-positioning variables), $\alpha_{1}$ to $\alpha_{14}$ represent regression coefficients, and $\beta$ is the intercept of the model. Wear factors were entered in the regression model using a backward-selection approach to reassure the exclusion of redundant variables. As previously reported [8], two cases per predictor variable are adequate for estimation of regression coefficients, standard errors, and CIs in MLR modeling, a condition which was just met in this study. The prediction ability of the constructed models then was tested by the leaveone-out cross-validation technique [40]. The cross-validation procedure was repeated until each patient was used as the test subject in his or her corresponding wear group.

ANN can be considered a nonlinear regression model that can model the relationship between the independent variables (predictors) and dependent variable in an analogous fashion to linear regression [4-7, 38]. The most-featured difference between linear regression and ANN is that the latter splits a complex nonlinear relationship into several piecewise approximations, where each approximation is generated as a nonlinear function of predictors (instead of a simple linear combination of predictors as in linear regression). ANN was used to predict the wear rate from the 14 inputs (same variables as above) for each wear class. The proposed ANN structure consisted of processor units (neurons) organized in layered arrangements. In each layer, neurons were related to the neurons of the next layer via weights (Fig. 2). Each input node was related to each mid-level neuron (called hidden neurons) via input weights. Thus, a weighted combination of all input parameters was fed into each hidden neuron where a nonlinear function (func), a hyperbolic tangent sigmoid, determined the wear-rate output of the hidden neuron (representing a nonlinear regression). A pure line function at each output then was used to combine all the piecewise nonlinear regressions produced by the hidden neurons. Using the above ANN structure, the linear wear rate was modeled as:

$$
\begin{aligned}
\text { Wear rate }= & \alpha_{1} \times \mathrm{y}_{1}+\alpha_{2} \times \mathrm{y}_{2}+\alpha_{3} \times \mathrm{y}_{3}+\cdots+\alpha_{\mathrm{n}} \\
& \times \mathrm{y}_{\mathrm{n}}+\beta \mathrm{n}=\text { number of hidden neurons }
\end{aligned}
$$

Where:

$\mathrm{y}_{\mathrm{i}}=\operatorname{func}\left(\mathrm{x}_{1}, \mathrm{x}_{2}, \mathrm{x}_{3}, \ldots+\mathrm{x}_{14}\right)+\eta_{\mathrm{i}} \quad 1<\mathrm{i}<\mathrm{n}$

Where $y_{1}$ to $y_{n}$ are the outputs from hidden neurons, $\beta$ is the intercept related to the ANN output, and $\eta_{\mathrm{i}}$ is the intercept related to each hidden neuron and $x_{1}$ to $x_{14}$ 
Table 4. Comparison of component positioning among three wear groups

\begin{tabular}{|c|c|c|c|c|c|c|c|}
\hline Variable & Group 1 & Group 2 & Mean difference & Standard error & $95 \% \mathrm{CI}$ & p Value & Bonferroni $\mathrm{p}$ value \\
\hline \multirow[t]{3}{*}{ C-INCL } & Low & Moderate & -2.77 & 1.83 & -6.42 to 0.87 & 0.134 & 1.000 \\
\hline & Low & High & -0.71 & 2.04 & -4.78 to 3.36 & 0.729 & 1.000 \\
\hline & High & Moderate & -2.07 & 1.98 & -6.01 to 1.88 & 0.300 & 1.000 \\
\hline \multirow[t]{3}{*}{ C-ANTE } & Low & Moderate & -2.99 & 1.85 & -6.68 to 0.70 & 0.110 & 1.000 \\
\hline & Low & High & -0.93 & 2.06 & -5.04 to 3.18 & 0.654 & 1.000 \\
\hline & High & Moderate & -2.06 & 2.00 & -6.05 to 1.93 & 0.306 & 1.000 \\
\hline \multirow[t]{3}{*}{ H-SET } & Low & Moderate & 1.31 & 2.21 & -3.19 to 5.81 & 0.558 & 1.000 \\
\hline & Low & High & -3.21 & 2.47 & -8.22 to 1.81 & 0.203 & 1.000 \\
\hline & High & Moderate & 4.52 & 2.14 & $0.16-8.87$ & 0.042 & 0.764 \\
\hline \multirow[t]{3}{*}{ V-SET } & Low & Moderate & 0.61 & 1.33 & -2.04 to 3.26 & 0.648 & 1.000 \\
\hline & Low & High & 3.27 & 1.48 & $0.31-6.22$ & 0.031 & 0.551 \\
\hline & High & Moderate & -2.66 & 1.42 & -5.49 to 0.18 & 0.066 & 1.000 \\
\hline \multirow[t]{3}{*}{ C-MED } & Low & Moderate & -0.65 & 1.22 & -3.10 to 1.79 & 0.596 & 1.000 \\
\hline & Low & High & 1.02 & 1.37 & -1.71 to 3.74 & 0.458 & 1.000 \\
\hline & High & Moderate & -1.67 & 1.32 & -4.31 to 0.97 & 0.211 & 1.000 \\
\hline \multirow[t]{3}{*}{ ABD-L } & Low & Moderate & 0.78 & 2.21 & -3.73 to 5.29 & 0.726 & 1.000 \\
\hline & Low & High & -0.25 & 2.45 & -5.26 to 4.76 & 0.919 & 1.000 \\
\hline & High & Moderate & 1.03 & 2.12 & -3.31 to 5.37 & 0.631 & 1.000 \\
\hline
\end{tabular}

$\mathrm{C}$-INCL = cup inclination; $\mathrm{C}-\mathrm{ANTE}=$ cup anteversion; V-SET $=$ vertical offset; C-MED = cup medialization; $\mathrm{ABD}-\mathrm{L}=$ abductor lever arm.

represent the wear factors (age, gait, and component-positioning variables). A gradient-descent back-propagation algorithm with adaptive learning rate was used to train the ANN. A class-specific ANN was assigned to each wear group (low, moderate, and high). In each wear group, patients were randomly divided in three subgroups: $70 \%$ of the patients were used to train the ANN (that is, adjust the weights and biases), $15 \%$ were used to validate the trained $\mathrm{ANN}$, and the remaining $15 \%$ were used to challenge the trained ANN with new patients and investigate the generalizability of the trained ANN. The prediction accuracy of the trained ANN then was evaluated by comparing ANN estimations versus radiographbased readings using normalized-root-mean-square error (NRMSE \%) and Pearson correlation coefficients. To achieve a 95\% CI for prediction accuracy, the training and testing procedures were iterated for 100 times, as suggested by Iyer and Rhinehart [24]. The prediction accuracy of the ANN then was averaged over all the iterations. The ANN structures were established using Neural Network Toolbox ${ }^{\mathrm{TM}}$ (MathWorks ${ }^{\circledR}$, Natick, MA, USA).

\section{Statistical Analysis}

Statistical analysis was conducted using SPSS Version 15.0. Demographic characteristics of participants (age, height, body weight) and all other variables of interest (wear rate, gait, and positioning factors) were compared among patients with high, moderate, and low wear using one-way ANOVA with a significance level of $p=0.05$ and Bonferroni-adjusted post hoc tests. Before the analysis, the presence of outliers was checked using boxplots. The normality of the data and homogeneity of variances also were tested using the Shapiro-Wilk and Levene's tests respectively to assure reliability of the ANOVA. To assure the homogeneity of patient groups in terms of other wear covariates that were not the main focus of this study, the distribution of implant design, polyethylene material, and surgical approach across wear groups was investigated using Chi-square analysis.

\section{Results}

\section{Differences Among Patients By Wear Rate}

There were no group differences in terms of component positioning (Table 4) and gait (Table 5). This suggested that wear differences might be caused by a combination of wear factors rather than by individual variables. Noteworthy, all the VIF computations were less than 2.5. Of all 72 investigated variable combinations, the VIF was less than 2.0 in $86 \%$ and $93 \%$ of the patients for positioning and gait variables, respectively. We therefore concluded that the predictor variables are only weakly correlated with each other and multicollinearity is not of concern. Regarding output, a weak 
Table 5. Comparison of gait biomechanics among three wear groups

\begin{tabular}{|c|c|c|c|c|c|c|c|}
\hline & Group 1 & Group 2 & Mean difference & Standard error & $95 \% \mathrm{CI}$ & $\mathrm{p}$ Value & Bonferroni $\mathrm{p}$ value \\
\hline \multirow[t]{3}{*}{ Speed } & Low & Moderate & -0.025 & 0.048 & -0.120 to 0.070 & 0.604 & 1.000 \\
\hline & Low & High & 0.029 & 0.053 & -0.076 to 0.135 & 0.581 & 1.000 \\
\hline & High & Moderate & -0.054 & 0.051 & -0.157 to 0.048 & 0.296 & 1.000 \\
\hline \multirow[t]{3}{*}{ HROM } & Low & Moderate & -0.84 & 1.70 & -4.22 to 2.55 & 0.624 & 1.000 \\
\hline & Low & High & -1.45 & 1.89 & -5.23 to 2.32 & 0.446 & 1.000 \\
\hline & High & Moderate & 0.62 & 1.84 & -3.05 to 4.28 & 0.738 & 1.000 \\
\hline \multirow[t]{3}{*}{ HMXFLEX } & Low & Moderate & -0.28 & 0.58 & -1.43 to 0.88 & 0.635 & 1.000 \\
\hline & Low & High & 0.43 & 0.65 & -0.86 to 1.71 & 0.511 & 1.000 \\
\hline & High & Moderate & -0.70 & 0.63 & -1.95 to 0.55 & 0.266 & 1.000 \\
\hline \multirow[t]{3}{*}{ HMXEXT } & Low & Moderate & 0.12 & 0.30 & -0.466 to 0.713 & 0.678 & 1.000 \\
\hline & Low & High & -0.07 & 0.33 & -0.729 to 0.585 & 0.828 & 1.000 \\
\hline & High & Moderate & 0.20 & 0.32 & -0.442 to 0.833 & 0.544 & 1.000 \\
\hline \multirow[t]{3}{*}{ HMYADD } & Low & Moderate & 0.12 & 0.31 & -0.489 to 0.729 & 0.695 & 1.000 \\
\hline & Low & High & 0.16 & 0.34 & -0.519 to 0.839 & 0.640 & 1.000 \\
\hline & High & Moderate & -0.04 & 0.33 & -0.698 to 0.619 & 0.905 & 1.000 \\
\hline \multirow[t]{3}{*}{ HMYABD } & Low & Moderate & -0.33 & 0.20 & -0.74 to 0.08 & 0.109 & 1.000 \\
\hline & Low & High & -0.11 & 0.23 & -0.57 to 0.34 & 0.624 & 1.000 \\
\hline & High & Moderate & -0.22 & 0.22 & -0.66 to 0.22 & 0.324 & 1.000 \\
\hline \multirow[t]{3}{*}{ HMZINT } & Low & Moderate & 0.06 & 0.07 & -0.0733 to 0.2010 & 0.357 & 1.000 \\
\hline & Low & High & 0.07 & 0.08 & -0.0802 to 0.2257 & 0.346 & 1.000 \\
\hline & High & Moderate & -0.01 & 0.07 & -0.1573 to 0.1394 & 0.905 & 1.000 \\
\hline \multirow[t]{3}{*}{ HMZEXT } & Low & Moderate & 0.02 & 0.08 & -0.147 to 0.187 & 0.816 & 1.000 \\
\hline & Low & High & 0.05 & 0.09 & -0.135 to 0.237 & 0.585 & 1.000 \\
\hline & High & Moderate & -0.03 & 0.09 & -0.212 to 0.149 & 0.728 & 1.000 \\
\hline
\end{tabular}

HROM = sagittal hip range of motion; HMXFLEX = maximum hip flexion moment; HMXEXT = maximum hip extension moment; HMYADD = maximum hip adduction moment; HMYABD = maximum hip abduction moment; HMZINT = maximum hip internal rotation moment; HMZEXT = maximum hip external rotation moment.

association between wear rate and time in situ was found (adjusted $\mathrm{R}^{2}=0.09$ ) (Fig. 3). Regarding secondary variables, there were no statistical differences in terms of implant design or polyethylene among the three wear groups. However, 'surgeon' (or surgical approach) showed a difference: Surgeon 2 (who used an anterolateral approach) had a larger number of patients in the high-wear group compared with Surgeon 1 (who used a posterior approach) (Table 6). No group differences were found in demographic characteristics such as age, height, and weight (Table 7).

Can We Predict Wear Rate Using Gait and Positioning Variables?

The level of wear rate (high, moderate, low) was predictable based on wear factors (gait and positioning variables) using the following classification rules:

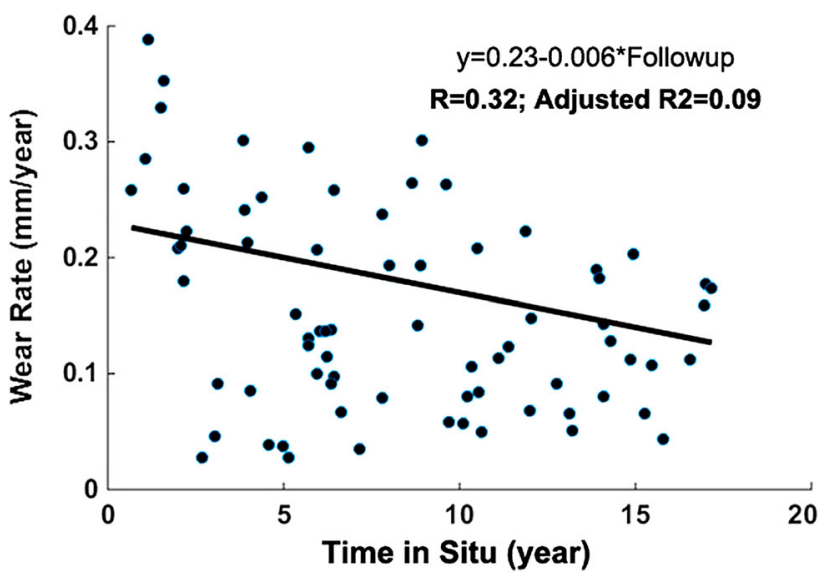

Fig. 3 The association between time in situ and wear rate represented a weak correlation (adjusted $\mathrm{R}^{2}=0.09$ ). 
Table 6. Chi-square distribution of cup, stem, polyethylene, and surgical approach among the three wear groups

\begin{tabular}{|c|c|c|c|c|}
\hline \multirow[t]{2}{*}{ Variable } & \multicolumn{3}{|c|}{ Wear group } & \multirow[t]{2}{*}{$\mathrm{p}$ Value } \\
\hline & High & Low & Moderate & \\
\hline \multicolumn{5}{|l|}{ Cup } \\
\hline HG I & 3 & 11 & 13 & \multirow{4}{*}{0.124} \\
\hline HG II & 6 & 9 & 7 & \\
\hline Mark II & 2 & 1 & 4 & \\
\hline Trilogy $^{\circledR}$ & 8 & 4 & 5 & \\
\hline \multicolumn{5}{|l|}{ Stem } \\
\hline Cemented & 5 & 7 & 3 & \\
\hline Cementless & 14 & 18 & 26 & 0.215 \\
\hline \multicolumn{5}{|l|}{ Polyethylene } \\
\hline GUR 1050 & 8 & 4 & 5 & \multirow[b]{2}{*}{0.917} \\
\hline GUR 4150 & 11 & 21 & 24 & \\
\hline \multicolumn{5}{|c|}{ Surgical approach } \\
\hline Anterolateral & 12 & 6 & 1 & \\
\hline Posterior & 17 & 17 & 26 & 0.002 \\
\hline
\end{tabular}

Membership-of-high-wear-group

$$
\begin{aligned}
= & 1.2 \times(\mathrm{C}-\mathrm{INCL})+1.6 \times(\mathrm{C}-\mathrm{MED})+2.4 \\
& \times(\mathrm{HMXFLEX})-0.4 \times(\mathrm{HMXEXT})+8.7 \\
& \times(\mathrm{HMYADD})+8.6 \times(\mathrm{HMYABD})-24.9 \\
& \times(\mathrm{HMZINT})-19.9 \times(\mathrm{HMZEXT})-69.8
\end{aligned}
$$

Eachsubjectthenwasassignedtotheweargroupwiththehighest membershipvalue.Eightypercentofpatientswithlowwearrate, $87 \%$ withmoderate wearrate, and $73 \%$ withhighwearratewere correctly classified (Table 8 ). This part of the wear prediction model(LDA) will allow assignment of any future patient to the appropriate wear class without prior knowledge of wear rate. Once subjects were classified according to wear, the MLR (Fig. 4)andANN(Fig. 5)wereabletosuccessfullypredictwear rate from wearfactors (age, gait, and implant positioning). The MLR-based predictive model consisted of the following three equations:

MLR models:

Wear rate $=\left\{\begin{array}{l}=-0.27 * \text { Age }+0.22 * \text { HROM }-0.22 * \text { HMXEXT }+0.6 * \text { HMYABD }-0.33 * \text { HMZINT }-0.24 * \text { HMZEXT For low-wear group } \\ =0.13 * \text { Age }+0.55 *(\mathrm{ABD}-\mathrm{L})-0.38 * \mathrm{HROM}+0.47 * \mathrm{HMXFLEX}-0.45 * \mathrm{HMYABD} \text { For moderate-wear group } \\ =-0.54 * \mathrm{C}-\mathrm{MED}-0.55 * \mathrm{HMYADD}+0.38 * \mathrm{HMZINT}+0.40 * \mathrm{H}-\mathrm{SET}-0.4 * \mathrm{C} \text {-INCL For high-wear group }\end{array}\right.$ ANN-based predictive model consisted of the three following equations:

\footnotetext{
$\left\{\begin{aligned}= & 0.050 \times f u n c(\text { Age })+0.15 \times f u n c(\text { HMXFLEX })-0.17 \times f u n c(\text { HMYABD })+0.19 \times f u n c(\text { HMZINT })-0.21 \times f u n c(\text { HMZEXT })+0.25 \times f u n c(\text { HROM }) \quad \text { For low-wear group } \\ = & 0.0030 \times f u n c(\text { Age })+0.32 \times f u n c(\text { ABD-L })+0.35 \times f u n c(\text { HROM })+0.27 \times f u n c(\text { HMXFLEX })+0.32 \times f u n c(\text { HMXEXT })-0.24 \times(\text { HMYADD })-0.18 \times f u n c(\text { HMYABD }) \\ & +0.17 \times f u n c(\text { HMZINT })-0.15 \times f u n c(\text { HMZEXT }) \quad \text { For moderate-wear group }\end{aligned}\right.$

Membership-of-low-wear-group

$$
\begin{aligned}
= & 1.1 \times(\mathrm{C}-\mathrm{INCL})+1.8 \times(\mathrm{C}-\mathrm{MED})+2.5 \\
& \times(\mathrm{HMXFLEX})-1.2 \times(\mathrm{HMXEXT})+8.5 \\
& \times(\mathrm{HMYADD})+6.8 \times(\mathrm{HMYABD})-21.6 \\
& \times(\mathrm{HMZINT})-15.0 \times(\mathrm{HMZEXT})-68.7
\end{aligned}
$$

Membership-of-moderate-wear-group

$$
\begin{aligned}
= & 1.4 \times(\mathrm{C}-\mathrm{INCL})+1.9 \times(\mathrm{C}-\mathrm{MED})+2.8 \\
& \times(\mathrm{HMXFLEX})-2.4 \times(\mathrm{HMXEXT})+10.1 \\
& \times(\mathrm{HMYADD})+10.6 \times(\mathrm{HMYABD})-29.7 \\
& \times(\mathrm{HMZINT})-20.2 \times(\mathrm{HMZEXT})-85.4
\end{aligned}
$$

In which "func" refers to tangent sigmoid function modeling the nonlinearity aspects of the interaction between wear factors and wear.

The ANN model provided higher prediction accuracy when compared with the actual wear data. For patients with low- and moderate-wear rates, the average prediction errors of the ANN model were NRMSE $8 \%$ and $11 \%$ respectively, while those of the MLR model were NRMSE 27\% and 54\%. Thus, ANN outperformed the MLR model which became even more evident when the wear of the high-wear group was predicted. For patients with a high wear rate, the ANN predicted wear with an average prediction error of NRMSE 14\%, while the prediction error for the MLR model was NRMSE $43 \%$. 
Table 7. Comparison of patient demographics and wear rates among three wear groups

\begin{tabular}{lllccccc}
\hline Variable & Group 1 & Group 2 & Mean difference & Standard error & 95\% CI & p Value & Bonferroni p value \\
\hline Age (years) & Low & Moderate & 3.27 & 2.62 & -1.96 to 8.50 & 0.217 & 1.000 \\
& Low & High & 5.36 & 2.92 & -0.47 to 11.20 & 0.071 & 0.851 \\
& High & Moderate & -2.10 & 2.84 & -7.76 to 3.56 & 0.462 & 1.000 \\
Height (m) & Low & Moderate & -0.035 & 0.023 & -0.082 to 0.011 & 0.137 & 1.000 \\
& Low & High & -0.033 & 0.026 & -0.085 to 0.019 & 0.214 & 1.000 \\
& High & Moderate & -0.002 & 0.025 & -0.053 to 0.048 & 0.922 & 1.000 \\
Weight $(\mathrm{N})$ & Low & Moderate & -36.3 & 43.6 & -123 to 51 & 0.408 & 1.000 \\
& Low & High & -84.0 & 48.6 & -181 to 13 & 0.088 & 1.000 \\
Linear wear rate (mm/year) & High & Moderate & 47.7 & 47.1 & -46 to 142 & 0.315 & 1.000 \\
& Low & Moderate & -0.088 & 0.010 & -0.11 to -0.07 & 0.000 & 0.000 \\
& High & Moderate & 0.119 & 0.0 & -0.23 to -0.19 & 0.000 & 0.000 \\
& & & -0.207 & $0.10-0.14$ & 0.000 & 0.000 \\
\hline
\end{tabular}

Table 8. Comparison between the actual wear level (determined based on radiography followups) and the predicted wear level (from LDA technique)

\begin{tabular}{lcccc}
\hline Actual wear level & \multicolumn{2}{l}{ Estimated wear level } & & H correctly classified \\
\cline { 2 - 5 } & Low & Moderate & 3 & $80 \%$ \\
\hline Low & 20 & 2 & 3 & $86 \%$ \\
Moderate & 1 & 25 & 15 & $79 \%$
\end{tabular}

Twenty of 25 patients with low wear rate were correctly classified as "low-wear"; 25 of 29 with moderate wear rate were correctly classified as "moderate wear"; 15 of 19 with high wear rate were correctly classified as high wear.

\section{Does Gait or Positioning Contribute More to Wear Rate?}

Gait was found to have a greater influence on the wear rate than surgical positioning variables. In both predictive models (ANN and MLR), gait variables explained between $42 \%$ to $60 \%$ of wear rate while positioning factors only explained between $10 \%$ to $33 \%$ of the wear rate. It seemed that positioning variables became more important in patients with high wear rate. For example, in patients with high-wear rate cup medialization and cup inclination angle emerged as part of the predictive models.

\section{Discussion}

Wear, a major barrier for implant longevity, has been greatly reduced with the introduction of crosslinked polyethylene. However, at present it is unknown if the problem of wear has been completely resolved or just has been delayed to a later time in the lifetime of the prosthesis. Therefore, it makes sense to further investigate the factors governing wear in the hopes of better understanding (and perhaps being able to influence) those factors. Patientspecific variables, such as gait or implant positioning, play an important role in wear. However, before this report, to our knowledge, no study with a rigorous model capable of predicting wear rate based on these variables has been published. Therefore, in the current study, we developed a predictive wear model based on subject-specific gait and implant-positioning variables. Our predictive model showed that (1) cup medialization and inclination angle plus three-dimensional hip moments can predict the level of wear rate (low, moderate, or high); (2) hip moments are more important than positioning factors (as they emerged with a higher contribution in the predictive models); (3) cup-positioning variables, such as medialization and inclination angle, become more important in the presence of high wear rates.

This study had several limitations. Perhaps the most important limitation was that patient activity was not included in the model. It is known from wear simulators that polyethylene wear increases linearly with cycles [13]. It has been shown that patient steps throughout the day play a critical role in the wear of polyethylene, and it as been postulated that "wear is a function of use not time" [43]. In 

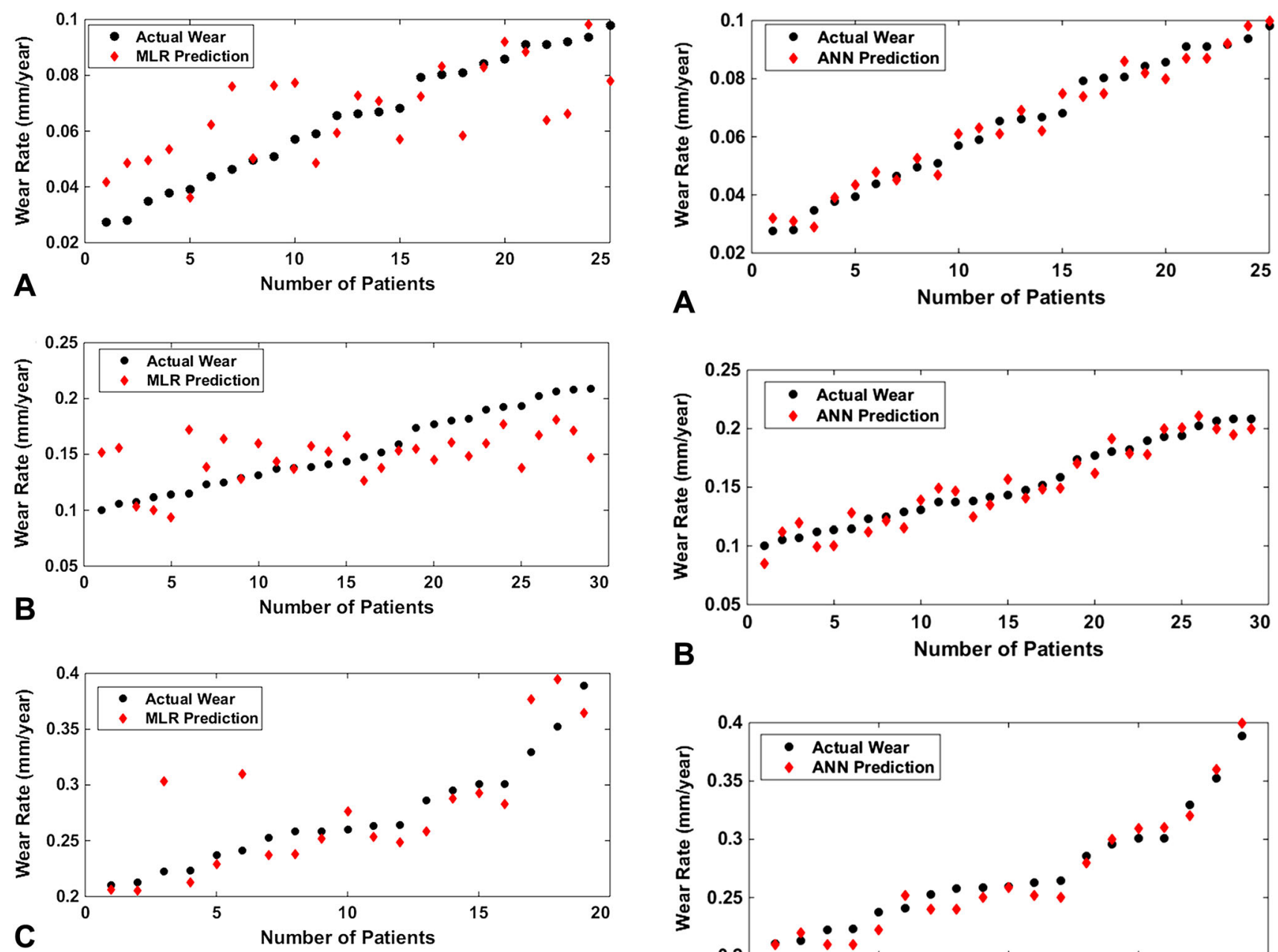

Fig. 4A-C Class-specific linear regression predictions of linear wear rate compared with radiographic wear assessment for patients with (A) low wear, (B) moderate wear, and (C) high wear are shown. MLR $=$ multiple linear regression.

the current study, the number of daily performed steps was unknown, as were the specific activities. We therefore used age as a surrogate for steps per day [37] in the analyses. We found that age was dropped from most regression models, and if present, entered as a nonsignificant variable. Since the meta-regression by Naal and Impellizzeri [37] showed a relatively strong relation between age and steps per day, we propose that the patient's gait pattern is indicative of his or her activity pattern, a hypothesis that needs to be verified in the future.

In terms of other limitations, we note that our study design allowed statistical associations to be drawn in the hopes of increasing prediction accuracy; however, no mechanisms and causes can be provided. However, it is interesting that gait pattern (together with positioning) is such a strong predictor for wear rate. In addition, the patients in this series all received THRs without crosslinked polyethylene (either GUR 415 or 1050). Generalizing our findings to newer materials should be

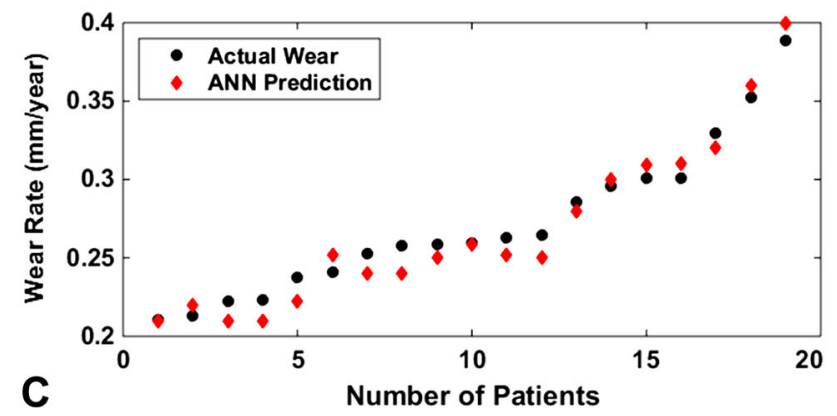

Fig. 5A-C Class-specific artificial neural network (ANN) predictions of linear wear rate compared with radiographic wear assessment for patients with (A) low wear, (B) moderate wear, and (C) high wear are shown.

done with caution as the influence and ranking of the wear factors may vary depending on implant material and design. However, the methodology (a two-step wear-predictive model consisting of a linear classifier and a regression model) is equally applicable to other types of implant design and material. Moreover, wear is a function of other variables such as implant design, material, and surgical approach that are not part of our proposed model. We attempted to control the potential influence of these variables by choosing patients with similar implant design and material. There were no statistical differences in terms of implant design or polyethylene type among the three wear groups, but 'surgeon' emerged as a potential confounder. Surgeon 2 had a larger number of patients in the high-wear group compared with Surgeon 1. Although this might be related to surgical approach, we believe it is a case-distribution issue in that Surgeon 2 may have worked 
on more-complex cases. Unfortunately, this retrospective study does not allow a more-definite conclusion. Future studies on a larger patient population with a heterogeneous distribution of implant design and surgical technique may consider these variables as additional predictors.

In addition, patients underwent only one gait test that was conducted 1 year after surgery, whereas radiographic followups continued for several years after surgery. Patients' gait may have changed with time as a function of age, rehabilitation, or weight gain or loss, that is not accounted for in this study. Further, the hip center has been assumed to be at a point $2.5 \mathrm{~cm}$ below the mid-point of a line that runs from the anterior superior iliac crest to the pubic tubercle. We did not compare this preassumed location versus hip centers calculated from the radiographs. However, Kirkwood at al. [26] reported that this hip center leads to the least error in the hip moment calculation (0.4 $\mathrm{Nm} / \mathrm{kg}$ in the frontal plane, $0.07 \mathrm{Nm} / \mathrm{kg}$ in the sagittal plane, and $0.03 \mathrm{Nm} / \mathrm{kg}$ in the transverse plane). Ten of our patients had only two radiographs each; therefore, the quality of these wear-rate calculations may have suffered. Two observers independently measured the wear rate, and only patients with an ICC greater than 0.90 were included. This makes the inclusion of reading errors unlikely, but cannot account for inferior radiographs in the first place. Moreover, two patients with wear rates between 0.4 and 1.0 $\mathrm{mm}$ per year $(0.68$ and $0.97 \mathrm{~mm} / \mathrm{year})$ were excluded from our study. These two patients were not removed because of having a high wear rate but because their wear rate was more than three times the interquartile range from the rest of the data and caused a prediction gap in the dataset. Ignoring these outliers would have affected the prediction accuracy of the MLR and ANN. For example, the accuracy of the ANN would have been reduced by $10 \%$. For these prediction models it is necessary to have a sufficient number of patients to uniformly cover the whole data range. In the future the model could be expanded to include extreme wear.

Historically, gait pattern has not been implicated as a wear factor of polyethylene in THR, but for the first time, to our knowledge, we document this relationship. Despite the availability of newer materials that seem to marginalize the wear problem, the observed relationship is of more than academic value. A patient's gait pattern provides information beyond loading of the hip during walking and should be considered a potential (mechanical) biomarker. In addition, the interdependence between component positioning and gait in the wear outcome is clinically relevant. Thus, to minimize wear, the ideal placement of implant components should be determined from the individual gait pattern. In the future, with the availability of modern technology (such as inertial measurement units), gait analysis will become a more-widespread and accessible tool in hospitals. Therefore, a patient's gait pattern should become part of the clinical evaluation for THR. A predictive wear model then might identify individual wear factors, which are modifiable, either during surgery with the appropriate component placement or after surgery through gait retraining.

Our predictive wear model consists of two steps: (1) LDA to estimate the level of wear (low, moderate, or high) from gait and implant-positioning parameters, and (2) ANN (or MLR) to further estimate the contribution of wear factors and the exact wear value. Before designing such a two-step predictive model, we attempted to design a one-step wearpredictive model that consisted of only one regression model (ANN or MLR). The models could predict the wear rate with an average accuracy of $65 \%$ for ANN and $32 \%$ for MLR. The low prediction accuracy may be related to two reasons: (1) there is no reasonable relationship between input and output and (2) the statistical model is only incompletely trained. In our case, we believe the latter is true, because the limited number of patients (73) and high interpatient variability of wear rates (range, 0.001-0.4) prevented meaningful training of a one-step ANN model. In addition, for the two-step model herein, a priori knowledge of a patient's wear class is not required and knowledge of gait and implant-positioning variables are sufficient.

Our predictive model showed that patient-specific wear rates are associated with the patients' gait patterns. Gait was found to have a greater influence on the wear rate than surgical positioning variables, which suggests that gait analysis should become part of the clinical evaluation process for THR. We believe that the consideration of individual gait bears potential to further reduce implant wear. In the future, a predictive wear model might identify individual wear factors that could be modified during surgery or after surgery through gait retraining. Although the findings are based on traditional polyethylene, the concept is applicable to modern materials.

Acknowledgments We thank Danas Bagdonas BS (Department of Orthopedics, Rush University Medical Center) for reading the radiographs and contributing as a second observer to the wear analysis. We also thank the surgeons, Jorge O. Galante MD, ScD and Aaron G. Rosenberg MD (both from the Department of Orthopedics, Rush University Medical Center) who performed the total hip replacements.

\section{References}

1. Affatato S. The history of biomaterials used in total hip arthroplasty (THA). Perspectives in Total Hip Arthroplasty: Advances in Biomaterials and their Tribological interactions. Sawston, UK: Woodhead Publishing; 2014:19-36.

2. Alvarez-Vera M, Contreras-Hernandez GR, Affatato S, Hernandez-Rodriguez MA. A novel total hip resurfacing design with improved range of motion and edge-load contact stress. Materials Design. 2014;55:690-698. 
3. Andriacchi TP, Strickland AB. Gait analysis as a tool to assess joint kinetics. In Berme N, ed. Biomechanics of Normal and Pathological Human Articulating Joints. Dordrecht, Netherlands: Springer Netherlands. 1985:83-102.

4. Ardestani MM, Chen Z, Wang L, Lian Q, Liu Y, He J, Li D, Jin Z. A neural network approach for determining gait modifications to reduce the contact force in knee joint implant. Med Eng Phys. 2014;36:1253-1265.

5. Ardestani MM, Moazen M, Chen Z, Zhang J, Jin Z. A real-time topography of maximum contact pressure distribution at medial tibiofemoral knee implant during gait: application to knee rehabilitation. Neurocomputing. 2015;154:174-188.

6. Ardestani MM, Moazen M, Jin Z. Gait modification and optimization using neural network-genetic algorithm approach: application to knee rehabilitation. Expert Systems Applications. 2014;41:7466-7477.

7. Ardestani MM, Zhang X, Wang L, Lian Q, Liu Y, He J, Li D, Jin Z. Human lower extremity joint moment prediction: a wavelet neural network approach. Expert Systems Applications. 2014;41:4422-4433.

8. Austin PC, Steyerberg EW. The number of subjects per variable required in linear regression analyses. $J$ Clin Epidemiol. 2015;68:627-636.

9. Australian Orthopaedic Association National Joint Replacement Registry. Annual Report 2015: Hip and Knee arthroplasty. Available at: https://aoanjrr.sahmri.com/en/annual-reports-2015. Accessed March 15, 2016.

10. Bennett D, Humphreys L, O'Brien S, Kelly C, Orr JF, Beverland DE. Wear paths produced by individual hip-replacement patients: a largescale, long-term follow-up study. J Biomech. 2008;41:2474-2482.

11. Berzins A, Sumner DR, Galante JO. Dimensional characteristics of uncomplicated autopsy-retrieved acetabular polyethylene liners by ultrasound. J Biomed Mater Res.1998;39:120-129.

12. Charnley J. Low friction principle. Low Friction Arthroplasty of the Hip. New York, NY: Springer-Verlag; 1979:3-15.

13. Clarke IC, Gustafson A, Jung H, Fujisawa A. Hip-simulator ranking of polyethylene wear: comparisons between ceramic heads of different sizes. Acta Orthop Scand. 1996;67:128-132.

14. Davey SM, Orr JF, Buchanan FJ, Nixon JR, Bennett D. The effect of patient gait on the material properties of UHMWPE in hip replacements. Biomaterials. 2005;26:4993-5001.

15. Delaunay C, Hamadouche M, Girard J, Duhamel A; SoFCOT Group. What are the causes for failures of primary hip arthroplasties in France? Clin Orthop Relat Res. 2013;471:3863-3869.

16. Domb BG, El Bitar YF, Sadik AY, Stake CE, Botser IB. Comparison of robotic-assisted and conventional acetabular cup placement in THA: a matched-pair controlled study. Clin Orthop Relat Res. 2013;472:329-336.

17. Donaldson FE, Nyman E Jr, Coburn JC. Prediction of contact mechanics in metal-on-metal total hip replacement for parametrically comprehensive designs and loads. $J$ Biomech. 2015;48:1828-1835.

18. Elkins JM, Callaghan JJ, Brown TD. Stability and trunnion wear potential in large-diameter metal-on-metal total hips: a finite element analysis. Clin Orthop Relat Res. 2014;472:529-542.

19. Elkins JM, Callaghan JJ, Brown TD. The 2014 Frank Stinchfield Award: The "landing zone" for wear and stability in total hip arthroplasty is smaller than we thought: a computational analysis. Clin Orthop Relat Res. 2015;473:441-452.

20. Foucher KC, Hurwitz DE, Wimmer MA. Do gait adaptations during stair climbing result in changes in implant forces in subjects with total hip replacements compared to normal subjects? Clin Biomech (Bristol, Avon). 2008;23:754-761.

21. Foucher KC, Hurwitz DE, Wimmer MA. Relative importance of gait vs. joint positioning on hip contact forces after total hip replacement. J Orthop Res. 2009;27:1576-1582.
22. Garvin KL, Hartman CW, Mangla J, Murdoch N, Martell JM. Wear analysis in THA utilizing oxidized zirconium and crosslinked polyethylene. Clin Orthop Relat Res. 2009;467:141-145.

23. Hamilton WG, Hopper RH, Ginn SD, Hammell NP, Engh CA Jr, Engh CA. The effect of total hip arthroplasty cup design on polyethylene wear rate. J Arthroplasty. 2005;20(7 suppl 3):63-72.

24. Iyer MS, Rhinehart RR. A method to determine the required number of neural-network training repetitions. IEEE Trans Neural Netw. 1999;10:427-432.

25. Imbuldeniya AM, Walter WL, Zicat BA, Walter WK. Cementless total hip replacement without femoral osteotomy in patients with severe developmental dysplasia of the hip: minimum 15-year clinical and radiological results. Bone Joint J. 2014;96:1449-1454.

26. Kirkwood RN, Culham EG, Costigan P. Radiographic and noninvasive determination of the hip joint center location: effect on hip joint moments. Clin Biomech (Bristol, Avon). 1999;14:227235.

27. Korduba LA, Essner A, Pivec R, Lancin P, Mont MA, Wang A, Delanois RE. Effect of acetabular cup abduction angle on wear of ultrahigh-molecular-weight polyethylene in hip simulator testing. Am J Orthop (Belle Mead NJ). 2014; 43:466-471.

28. Kurtz SM, Ong KL. Contemporary total hip arthroplasty: alternative bearings. UHMWPE Biomaterials Handbook: Ultra High Molecular Weight Polyethylene in Total Joint Replacement and Medical Devices. 3rd ed. Oxford, UK: William Andrew Publishing/Elsevier; 2016:72-105.

29. Kurtz SM, Ong KL, Lau E, Bozic KJ. Impact of the economic downturn on total joint replacement demand in the United States: updaedf projections to 2021. J Bone Joint Surg Am. 2014;96:624630.

30. Leslie IJ, Williams S, Isaac G, Ingham E, Fisher J. High cup angle and microseparation increase the wear of hip surface replacements. Clin Orthop Relat Res. 2009;467:2259-2265.

31. Liao Y, Hoffman E, Wimmer M, Fischer A, Jacobs J, Marks L. CoCrMo metal-on-metal hip replacements. Phys Chem Chem Phys. 2013;15:746-756.

32. Lundberg HJ, Stewart KJ, Pedersen DR, Callaghan JJ, Brown TD. Nonidentical and outlier duty cycles as factors accelerating UHMWPE wear in THA: a finite element exploration. $J$ Orthop Res. 2007;25:30-43.

33. Martell JM, Berdia S. Determination of polyethylene wear in total hip replacements with use of digital radiographs. $J$ Bone Joint Surg Am. 1997;79:1635-1641.

34. Matsoukas G, Kim IY. Design optimization of a total hip prosthesis for wear reduction. J Biomech Eng. 2009;131:051003.

35. McLachlan GJ. Discriminant Analysis and Statistical Pattern Recognition. New York, NY: Wiley, John \& Sons; 2004.

36. Mihalko WM, Wimmer MA, Pacione CA, Laurent MP, Murphy RF, Rider C. How have alternative bearings and modularity affected revision rates in total hip arthroplasty? Clin Orthop Relat Res. 2014;472:3747-3758.

37. Naal FD, Impellizzeri FM. How active are patients undergoing total joint arthroplasty? A systematic review. Clin Orthop Relat Res. 2009;468:1891-1904.

38. Orozco Villaseñor DA, Wimmer MA. Wear scar similarities between retrieved and simulator-tested polyethylene TKR components: an artificial neural network approach. Biomed Res Int. 2016;2016:2071945.

39. Perrin T, Dorr LD, Perry J, Gronley J, Hull DB. Functional evaluation of total hip arthroplasty with five-to ten-year follow-up evaluation. Clin Orthop Relat Res. 1985;195:252-260.

40. Picard RR, Cook RD. Cross-validation of regression models. $J$ Am Stat Assoc. 1984;79:575-583.

41. Pierannunzii L, Fischer F, d'Imporzano M. Retroacetabular osteolytic lesions behind well-fixed prosthetic cups: pilot study of bearings-retaining surgery. J Orthop Traumatol. 2008;9:225-231. 
42. Scheerlinck T. Cup positioning in total hip arthroplasty. Acta Orthop Belg. 2014;80:336-347.

43. Schmalzried TP, Shepherd EF, Dorey FJ, Jackson WO, dela Rosa M, Fa'vae F, McKellop HA, McClung CD, Martell J, Moreland JR, Amstutz HC. The John Charnley Award: Wear is a function of use, not time. Clin Orthop Relat Res. 2000;381:36-46.
44. Wong C, Stilling M. Polyethylene wear in total hip arthroplasty for suboptimal acetabular cup positions and for different polyethylene types: experimental evaluation of wear simulation by finite element analysis using clinical radiostereometric measurements. In Knahr K, ed. Tribology in Total Hip Arthroplasty. Berlin, Germany: Springer; 2011:135-158. 